\title{
Market-Sensing Capabilities, Profitability WITHIN STAGNANT INDUSTRIES AND CRAFTING OF Customer Value Propositions
}

\author{
JEFFREY YI-LIN FORREST*, ZAIWU GONG**, EDWARD SCOTT ${ }^{* * *}$, GERARDO ELOY SOTO RUIZ*****
}

\begin{abstract}
From the perspective of market competition, this paper investigates the impact of market-sensing capability on a company, and sources profits within a slow growth industry. As an example, our results are applied to demonstrate how effective customer value propositions can be formulated. Among others, it is shown that market-sensing capability empowers a company to categorize customers, lower its operational costs while increase expected profits; that when an industry experiences slow growth, its member company's profit can grow only through a combination of raising unit price and lowering unit cost; and how market knowledge and innovative understanding of market invitations potentially lead to effective CVPs. Instead of employing either a statistics-based approach or an anecdotal analysis, this work relies on the rigor of game theory so that all results established are generally true unless given conditions are violated. Managerial recommendations for decision makers and potential questions for future research are provided.
\end{abstract}

Keywords: customer relation; market invitation; market knowledge; market-level growth; Nash equilibrium; profit portfolio

JEL Classification: $M 10, M 31$

\section{INTRODUCTION}

Market-sensing, meaning innovative understanding of market signals and invitations, has been recognized as an important capability for a company that desires to survive and succeed in increasingly fast-changing markets (Day, 1994; Forrest et

\footnotetext{
* Department of Accounting, Economics and Finance, Slippery Rock University, Slippery Rock, PA 16057, USA; e-mail: jeffrey.forrest@ sru.edu

** College of Management Engineering, Nanjing University of Information Science and Technology, Nanjing 210044, China; zwgong26@163.com

**** Department of Accounting, Economics and Finance, Slippery Rock University, Slippery Rock, PA 16057, USA; e-mail: edward.scott@ sru.edu

***** Marketing Department, Autonomous University of the West, Blvd. Lola Beltrán and Blvd. Mario Lopez Valdes, CP 80020, Culiacán, Sinaloa, Mexico; e-mail: gerardo.soto@udo.mx
} 
al., 2017; McGrath, 2013). However, the literature reports inconsistent findings. For example, Ardyan (2016) does not find any positive effect of market-sensing capability on companies' profitability. Although such capability does show some positive effect on companies' profitability, Lindblom et al. (2008) confirms that the effect is not significant. However, in terms of positive findings, Sugiyarti and Ardyan (2017) confirm a positive effect of such capability on the quality of market entries; and Alshanty and Emeagwali (2019) demonstrate a significant impact on knowledge creation for small- and medium-sized enterprises. If these studies, either negative or positive, are seen holistically (Forrest, 2018), these empirically confirmed results are really obvious. For example, a company's ability to see a market trend does not mean that it is capable of actually taking appropriate actions to follow the trend. That is, between seeing and materializing what is seen there is a large room for many other things to occur (McGrath, 2013). As for the listed positive empirical findings, each market entry decision is generally made based on prior market sensing, while knowledge creation takes place after learning from the market. So, of course the capability of market sensing impacts market entry and knowledge creation positively. Although we can provide such holistic explanations for the inconsistency of the literature, an important general question still arises as follows: are there key factors that drive these inconsistent empirical findings?

The answer to this question is both theoretically and practically important, because whether it is for a market leader or a follower, knowing the evolving direction of future market demand and being able to actually take corresponding actions are crucial for managers to plan strategically and to make necessary adjustments, especially within the current era of transient competitive advantages (McGrath, 2013).

The primary contributions of the present research are threefold. First, to arrive at an answer to the present question, we have to methodologically go beyond the limitations of all statistics- and anecdote-based approaches. The literature is mostly empirical, which is why inconsistent results as listed above appear. And, it has been noted that in many situations, inconsistencies and difficult issues are simply consequences of the tools employed in studies (Einstein, 1997). Hence, instead of using statistics-based empirical studies or anecdote-based qualitive research, this paper utilizes game theory and the logical reasoning that is widely used in mathematics (Kline 1972). Second, by using game theory, we are able to conceptualize a company's potential for achieving and sustaining profitability in industries that experience stagnant market growth. Third, we offer a novel 
application of market knowledge and an innovative understanding of market signals to help companies formulate effective customer value propositions (CVPs).

The rest of this paper is organized as follows: Section 2 reviews relevant literature Section 3 shows the vital importance of market-sensing capabilities for companies that endeavor to succeed in the marketplace. Section 4 investigates profitability in industries that experience stagnant market growth. As applications of established results, Section 5 considers the association between customer relationship management capability \& profitability, and conditions under which effective CVPs can be drafted. This presentation concludes in Section 6 with managerial recommendations and appropriate questions for future research.

\section{LiterATURE REVIEW}

This work contributes to three areas of the literature: market-sensing capabilities, profitability in stagnant industries and formulation of CVPs. Studies on market-sensing capabilities have been mostly empirical and revealed inconsistent findings. For example, Bharadwaj and Dong (2014) show that market learning needs to cover all customers in order for a company to synchronize with market change and to deliver superior value. Ardyan (2016) and Lindblom et al. (2008) find respectively that market-sensing capability has no positive or significant effect on profitability. Sugiyarti and Ardyan (2017) demonstrate that market-sense capability positively and significantly affects the quality of market entry. Bayighomog Likoum et al. (2018) propose an empirical research agenda that links market-sensing capability and firm performance. Alshanty and Emeagwali (2019) confirm marketsensing capability's positive effect on knowledge creation for small and medium sized enterprises. The present research enriches the extant literature, while avoiding all constraints of statistics- and anecdote-based approaches, and reveals that marketsensing capability enables a company to identify target customers, to lower its average costs and to increase expected profits.

There is a paucity of literature concerning profitability in stagnant industries, all of which examine a particular industry or market. For instance, Ferber and Schlappa (2016) use good practices and a model to ivestigate how brownfield land can be managed more effectively and sustainably in stagnant European urban land markets. Tournois (2016) reveals how BB cream, a breakthrough product in the cosmetics market, brought about successful growth. Porse and Rudolph (2017) review the geography of the seaweed hydrocolloid industry and provide industrywide suggestions. Clements et al. (2019) address challenges faced by small-scale furniture productions in Jepara, Indonesia, by assessing a regional producers 
association. Le et al. (2020) investigate financial development and productivity growth in stagnant or low-productivity-growth U.S. industries. Contrary to these studies on specific industries and markets, this work has broad applicability to many industries lacking market growth.

Most of the literature on formulation of CVPs is oriented towards applications. For example, Osterwalder et al. (2014) list processes and tools that help produce and generate sales of companies' products that sell. By adapting this work to financial planners, Lecours (2017) provides a framework of CVP development. Wouters et al. (2018) recommend startups construct two sequential value propositions - the innovative offering and leveraging assistance value proposition - with the former demonstrating the superior value created for customer firms and the latter value captured by customer firms. Using what he terms the "service-dominant logic," Kowalkowski (2011) codifies four principles from the literature to guide a company as it designs its market opportunities. In comparison, using game theory the current research develops how market knowledge can help create effective CVPs and why innovative understanding of market invitations plays a key role in the creation of effective CVPs.

In sum, this work contributes to the literature in three different ways by: clarifying inconsistent empirical findings, deriving results that are broadly applicable to markets that satisfy given conditions, and establishing the importance of knowledge and innovative understanding of markets in the formulation of CVPs.

\section{VitAl IMPORTANCE OF MARKET-SEnSing CAPABILITIES}

To theoretically see why market-sensing capabilities are vitally important for companies, let us consider an oligopoly market, that is perfectly completive and served by $n$ incumbent companies, for $n=1,2,3, \ldots$ Assume that the operation of the market is only affected by market forces, such as demand and supply, which are influenced by consumers' forever evolving preferences and tastes. Implicitly, this assumption means that although technological advances affect the equilibrium between market demand and supply, the competition among rival companies is not influenced in any way by any other market. Assume that the $n$ incumbent companies serve the said market with their horizontally differentiated offers, $n=1,2,3, \ldots$ Although consumers' forever-evolving preferences and tastes tend to turn once loyal customers into switchers who make purchase decisions depending on which company's offer is valued more highly, assume that each incumbent company enjoys the support of its loyal customers as long as the prices are not more than their reservation prices. The existence of switchers means that there are customers in the 
marketplace who are not totally satisfied with any of the available market offers. For these switchers, assume that for whatever reason they make their purchases only from the company that offers the best price. Collectively, the totality of these switchers will be referred to as the consumer surplus in the marketplace. So, other than trying to keep their corresponding loyal customers, the incumbent companies compete with each other over the consumer surplus by using pricing strategies.

As for the managerial decision-making of the incumbent companies, assume that the companies' managers are well aware of competitors' pricing strategies so that they set prices that result in a Nash equilibrium to advance their best responses through untainted self-analyses. Then, the dynamics of competition in this market is of the following property:

Theorem 1. When the afore-mentioned market is in Nash equilibrium, if the percentage scale of consumer surplus is greater than that of the loyal-customer base of at least one incumbent company, then an opportunity appears for other companies to profitably enter the market with their versions of substitute offers so that the aggregate expected profit of all entrants can be potentially larger than that of at least one incumbent company.

Proof: Without loss of generality, assume that all boundary conditions are normalized as follows: for each company involved, its cost of production is 0 , customer's reservation price is 1 , its price $P$ satisfies $0 \leq P \leq 1$, its (percentage) magnitude of loyal customers is $u$ (same for all incumbent companies), and $v=1-$ $n u$ stands for the percentage magnitude of the consumer surplus. Also without loss of generality, assume that only one new company enters into the described market by randomizing its price between production cost 0 and reservation price 1 .

To protect their established territories and to exercise mutual forbearance (Bernheim and Whinston, 1990), each incumbent company sets its price by considering the entrant and other incumbents. If the entrant randomizes its price between its cost and customer reservation price, then the equilibrium indifference condition of incumbent Company $k$ is

$$
u \times P+v \times P \prod_{j \neq k}^{n}(1-P)\left[1-F_{j}(P)\right]=u \times 1
$$

where $F_{j}(P)$ represents the price distribution of company $j$, and in Nash equilibrium, the incumbent companies do not have any pure pricing strategy (Forrest et al., 2017). So, for the incumbent companies, their symmetric equilibrium pricing is 


$$
F(P)=1-\left(\frac{1-v}{v n P}\right)^{\frac{1}{n-1}}
$$

The assumption that the consumer surplus $v \geq u$ (= the magnitude of the loyal-customer base of at least one incumbent company) implies that equation (2) defines a mixed strategy for each incumbent company for $P$ satisfying $(1-v) /(v n) \leq P \leq 1$. Since $F(P)$ is discontinuous at $P=1$ with a jump $[(1-v) /(v n)]^{\frac{1}{n-1}}$, the expected profits of the entrant are:

$$
\begin{gathered}
E_{e}(\Pi)=\int_{0}^{(1-v) /(v n)} v P d P+\int_{(1-v) /(v n)}^{+\infty} v P[1-F(P)]^{n} d P \\
\frac{(1-v)^{2}}{2 v n^{2}}-\frac{(1-v)^{2}}{v n^{2}} \ln \frac{1-v}{v n}+v\left(\frac{1-v}{v n}\right)^{\frac{n}{n-1}}, \quad \text { if } n=2 \\
\frac{-(1-v)^{2}}{2 v n(n-2)}+\frac{n-1}{(n-2)}\left[\frac{(1-v)^{n}}{v n^{n}}\right]^{\frac{1}{n-1}}+v\left(\frac{1-v}{v n}\right)^{\frac{n}{n-1}}, \quad \text { if } n \geq 3
\end{gathered}
$$

The first term on right-hand side of equation (3) is equal to the entrant's expected profits when it charges a price lower than the incumbents and captures all switchers, and the second term is the entrant's expected profits when it directly competes with the incumbent companies. Additionally, the expected profits of an incumbent are

$$
\begin{aligned}
E_{m}(\Pi)= & \int_{(1-v) /(v n)}^{1}\left\{\frac{1-v}{n} P+v P(1-P) \prod_{j \neq i}^{n}[1-F(P)]\right\} d F(P) \\
& +\frac{1-v}{n}\left(\frac{1-v}{v n}\right)^{\frac{1}{n-1}}=\frac{1-v}{n} .
\end{aligned}
$$

Because $\frac{\partial}{\partial u}\left[E_{e}(\Pi)-E_{m}(\Pi)\right]>0$, and when $u=1 /(n+1)=v, E_{e}(\Pi)-$ $E_{m}(\Pi)>0$, there is $u^{*} \in(0,1 /(n+1))$ satisfying that when $u=(1-v) / n \geq u^{*}$, $E_{e}(\Pi)>E_{m}(\Pi)$. That is, the entrant can actually expect to make more profits in the said market than at least one incumbent, if the assumed normalizations are not applied. 
By market-sensing capability, it means such an aptitude that a company can employ to acquire an innovative understanding of market invitations. In other words, such capability represents a company's ability to shed creative light on its knowledge about its customers, competitors, members of its supply-chain ecosystem and the broader market environment in which it operates. This definition generalizes that introduced by Day (1994) and is different from Lindstrom et al (2008) in terms of that other than sensing the market our definition has nothing to do with using the innovative understanding of the market invitation to guide subsequent actions. Now, by examining this concept in the context of Theorem 1, the following result follows. Note: in the rest of this paper, the word "proposition" means one of two unrelated concepts: (1) a statement that is arguably true; or (2) a particular selling point, as well studied in the area of marketing, for example, the unique selling proposition (Reeves 1961), the emotional selling proposition (Lindstrom 2005), or customer value proposition (Payne et al. 2017). The meaning of "proposition" in (1) points to the methodological novelty of this paper: any hypothesis testing, as widely employed in economics and business studies, is a statistics-based approach that helps uncover potential facts, but not any arguably true fact.

Proposition 1. With a superb market-sensing capability, a company is able to

(1) Identify the market segments of customers who are not adequately served and customers who are unsatisfied with currently existing market offers; and

(2) Learn market insights that enable the company to lower its average costs through introducing appropriate technologies, acquiring and deploying adequate resources, etc., to meet evolving customer demands and prospective opportunities.

In fact, item (1) is a direct consequence of Theorem 1, where both underserved and unsatisfied customers jointly constitute the market segment of switchers. Because of customers' constantly evolving preferences and needs, currently satisfied customers can still become either unsatisfied or underserved, and become a switcher. So, a superb market-sensing capability helps a company to identify potential switchers. Theorem 1 implies that if there are switchers to target, new competitions will appear.

As for item (2), the appearance of new entrants into the market with the potential of making as much profit as some of the incumbent companies (Theorem 1) means particularly that if $v$ - the magnitude of the market segment of switchers is greater than that of the loyal-customer base of an incumbent company, then collectively the new entrants can potentially make more profits than some of the incumbent companies. For this outcome to happen realistically, it must be the case 
that the new entrants have acquired something, such as knowledge, technology, or managerial routine, that greatly lowers their average costs of production. Examples of this 'something' are a disruptive technology, a newly found breakthrough in managerial efficiency, or a more effective production capability. In sum, a superb market-sensing capability enables a company to acquire at least one of these resources to lower its average unit cost.

In terms of the literature, a more narrowly formulated conclusion than item (1) is given by Slater and Narver (2000); and a special case of item (2) is provided by Hult (1998) and Morgan et al (2009a).

Proposition 2. The stronger market-sensing capability a company possesses, the more profit the company can expect to earn.

To see why this result holds true in general, let us consider two scenarios: (1) the focal company operates in a munificent environment, where the demand is greater than the supply; and (2) the focal company conducts its business in an environment that lacks market growth, where the demand is less than or equal to the supply.

When scenario (1) holds true, the market provides the potential of simultaneous growth in both sales and margins; therefore, the company can expect to earn additional profits in these two dimensions. In this case, the market-sensing capability of the company helps it pinpoint where high demand is located, such as underserved market segments, and how its offers can be tailored to satisfy particular consumer needs that are not fulfilled by rivals' offers. Furthermore, this market knowledge enables the company to conduct a logistically effective sales efforts (Proposition 1 (1)) and fine tune its offers to reach a wider range of customers through either more focused CVPs or adjusting the features and/or functionalities of its offers accordingly (Proposition 1 (2)).

When scenario (2) is the case, the company can grow its profits in two ways (for more details, see Proposition 3 below): (i) expand its market territory through increasing unit sales to current customers, or acquiring new customers, or a combination of these two methods; and (ii) raise margins by either increasing the price for each unit of output sold, or lowering costs, or a combination of both. Under this scenario, a strong market-sensing capability will help the company to realize the exact situation within which it is situated, i.e., market growth is absent, so that appropriate actions can be taken to remedy the situation by possibly adjusting its offers to potentially attract additional customers from the current market or from other markets and by making its production more efficient than before (Morgan et al., 2009b). That is, stronger market-sensing capability leads to more profit potential. 


\section{Profitability Within Markets that Lack Market Growth}

For the purpose of growing profit, a company can generally increase sales revenue, margins or both. Other than the rare circumstances when demands exceed supplies (Dickson, 1992; Keats and Hitt, 1988), such as the cases of expanding markets, say, the personal computer market in the 1970s (Sobel, 1999), the general profit picture of a company is portrayed by the following proposition:

Proposition 3. If a focal company operates within an industry with no market growth, then it can grow its profit only by raising margins through some combination of the following strategies: raise the price for each unit sold or lower the cost of each unit sold.

To show this result, it suffices to demonstrate that under the given assumption about the industry (or market) within which the focal company operates, the company cannot effectively increase its sales revenue. In general, the goal of increasing sales revenue can be accomplished by either increasing unit sales to current customers or acquiring new customers or both.

Assume that the industry (or market) in which the focal company operates is occupied by $n$ incumbent companies, $n=1,2 \ldots$ They provide substitutable offers to their respective bases of loyal customers, if the price is not more than their reservation price. For the most general situation, the demands of these loyal customers are already satisfied by their respective companies. Thus, increasing sales of additional units of the same market offers to these customers is nearly impossible unless the price per unit value is lowered substantially and/or the demand increases from these loyal customers. In terms of increases in unit sales, enticing a loyal customer to make additional purchases is equivalent to the increase from acquiring a new customer. To acquire new customers, these incumbent companies have to compete against each other by using the strategy of adjusting their per unit-value prices, because it is assumed that they all serve the market with their mutually substitutable offers. The reality that the current business world is in the era of transient competitive advantages (McGrath, 2013) and customers become less patient than ever before (Forrest and Tallapally, 2018) implies that the market surely contains an increasing number of discontent customers with their quickly evolving preferences. Therefore, these customers, no matter whether they were previously loyal to their particular companies or not, become ready targets for the focal company to potentially acquire as new customers. Evidently, when adjustable per unitvalue prices are employed to attract potential new customers, the same prices have to be applied to loyal customers also in order to maintain their loyalty through fair treatment. Without loss of generality, assume that the forever improving efficiency of modern technology implies that the pricing strategies of the incumbent companies are 
known to each other. Then, to possibly acquire new customers, the incumbent companies play the Nash equilibrium through pure self-analyses.

The following game-theoretical analysis, which is a continuation of the proof of Theorem 1, shows that the expected profit of each incumbent company stays constant and is equal to how much it expects to earn from its base of loyal customers, although the incumbent companies try to attract as many new customers as possible. In other words, what is implied jointly by this analysis and the discussion above is that our focal company cannot effectively raise its sales revenue by increasing unit sales to current customers or acquiring new customers or both. To reach this conclusion of the argument for Proposition 3, let us look at some game-theoretic details below.

In the set-up given in the previous paragraphs, all incumbent companies are identical, as so normalized in the proof of Theorem 1. Hence, there is no pure strategy Nash equilibrium (Narasimhan, 1988; Forrest et al, 2017). To find a symmetric mixed strategy Nash equilibrium, assume that the price distribution of company $i$, $i \in\{1,2, \ldots, n\}$, is $F_{i}(P)$. Then, this company's objective function is

$$
\begin{aligned}
\max _{F_{i}} E\left(\Pi_{i}\right) & =\int_{-\infty}^{\infty}\left\{u P+\prod_{j \neq i}^{m}\left[1-F_{k}(P)\right] v P\right\} d F_{i}(P) \\
= & \int_{0}^{1}\left\{u P+\prod_{j \neq i}^{m}\left[1-F_{k}(P)\right] v P\right\} d F_{i}(P)
\end{aligned}
$$

where $E\left(\Pi_{i}\right)$ is the expected profit of company $i$ for all possible prices, and all other symbols are the same as those defined and normalized in the proof of Theorem 1. The company's objective is to maximize its expected profit by choosing its particular price distribution $F_{i}(P)$. The reason why the upper and lower limits of the integral are changed respectively from $+\infty$ and $-\infty$ to 1 and 0 is that when $P<$ 0 (= the cost of production) or when $P>1$ (= reservation price), the profits are zero.

Company $i$ can readily earn $u$ from its loyal customers by charging them the reservation price 1 . However, to potentially maximize profits and to protect its market territory (Theorem 1), each incumbent company likes to adjust price $P$ to attract new customers and to potentially exhaust the consumer surplus. At the same time each company does not have any incentive to price its product below $u /(u+v)$. If so, the price below $u /(u+v)$ will yield profit less than $u$ despite of attracting all discontent customers, because $u P+v P \geq u \rightarrow P \geq u /(u+v)$. From the equilibrium indifference condition for company $i$ 


$$
\begin{aligned}
u \times P+\prod_{j \neq i}^{n}\left[1-F_{k}(P)\right] v \times P=u \times 1, \frac{u}{u+v} \leq P \leq 1, i \\
=1,2, \ldots, n
\end{aligned}
$$

one obtains the symmetric equilibrium price distribution as follows

$$
F(P)=F_{i}(P)=F_{j}(P)=1-\left[\frac{(1-P) u}{P(1-n u)}\right]^{\frac{1}{n-1}}, \frac{u}{u+v} \leq P \leq 1
$$

satisfying $F(u /(u+v))=0$ and $F(1)=1$. Hence, each incumbent company's expected profit is

$$
\begin{gathered}
E(\Pi)=\int_{-\infty}^{+\infty}\left\{u P+\prod_{j \neq i}^{m}\left[1-F_{k}(P)\right] v P\right\} d F(P) \\
=\int_{\frac{x}{x+y}}^{1} u d F(P)=\left.u F(P)\right|_{\frac{u+v}{u+v}} ^{1}=u
\end{gathered}
$$

That is, in the symmetric mixed strategy Nash equilibrium, each incumbent company's expected profit does not change and is equal to how much it expects to earn from its base of loyal customers, even though it tries to acquire as many new customers as possible.

Proposition 4. If a focal company operates within an industry with no market growth, then profit growth from expanded sales revenue and that from margins, two components driving the company's profit, do not generally occur simultaneously.

To see why this result holds true in general, let us first look at the concept of resources. Specifically, by resource, it means a company's asset, either tangible or not (Harmancioglu et al., 2009), that can be employed to achieve its strategies (Barney and Arikan, 2001). In other words, a resource represents anything that a company can mobilize to achieve its corporate objectives through its adopted strategies. Assets can be physical, financial, informational, intellectual, or organizational.

Now, let us identify each company with its unique system of resources (Barney and Hesterly, 2012; Peteraf and Barney, 2003), where, for instance, among others each company has its own unique set of human resources and particular ways to utilize these human resources. Hence, the given assumption implies that: 
(1) In order to maintain or improve its sales revenue, a company has to grow its market share through increasing the number of units sold to existing customers and acquiring new customers, see the argument of Proposition 3. And

(2) In order to improve its margins, the company has to raise prices realized for each unit sold, lower costs, or use some combination of these two options.

To accomplish item (1), where Proposition 3 indicates that instead of improving sales revenue, it will be more likely a maintenance of sales revenue, the company needs to allocate a specific set of resources to exploit the market value of its existing offers; and to accomplish item (2), the company has to dedicate a different set of resources to either explore incremental improvements on the existing offers or produce completely new offers that feature more use values to customers than existing ones. However, resources, purposefully developed to accomplish (1) above and those for (2), generally do not work well together (McGrath, 2013) because these two business goals are inconsistent with each other. Of course, there are resources, such as relationships that lead to information sharing, risk taking, and adoption of innovations (Dutta et al., 1999), that can be easily deployed to realize different business goals.

Let $\mathrm{X}$ and $\mathrm{Y}$ be mutually exclusive sets of resources such that resources in $\mathrm{X}$ lead to the realization of item (1) and those in Y help with that of item (2). Then interactions between resources in $\mathrm{X}$ and those in $\mathrm{Y}$ tend to produce undesirable effects or outcomes. That is, profit in sales revenue and profit in margins do not generally increase simultaneously, because the effects of resources in $\mathrm{X}$ and those in $\mathrm{Y}$ tend to neutralize each other. The situation discussed here is depicted in Figure 1, where the sets of resources exclusively developed for business goals (1) and (2), respectively, do not overlap. Furthermore, the general-purpose resources can be deployed and redeployed readily to serve different, even opposing goals.

Preliminarily, different specific versions of the general conclusion in Proposition 4 were confirmed by various scholars, such as Markman and Gartner (2002) and Steffens et al. (2009). 


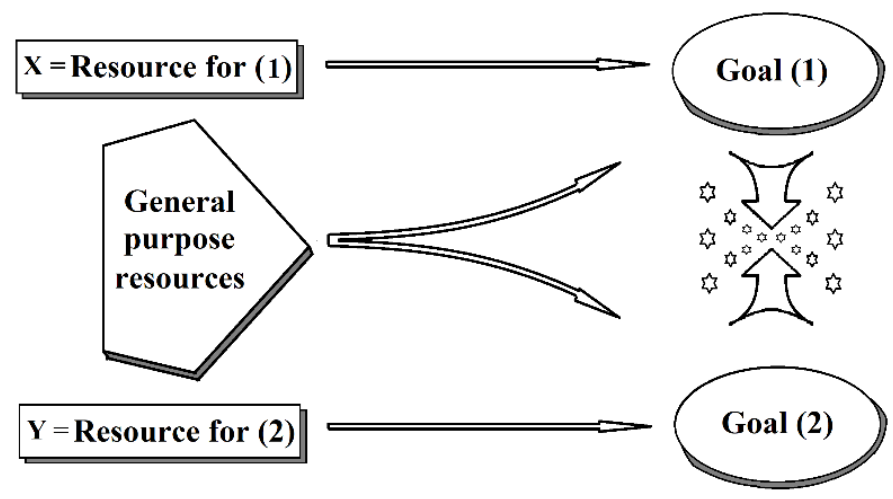

Figure 1: Separation of available resources

Proposition 4 leads to the following issues for managers: what should they do when it becomes clear (to them while not necessarily to others) that a competitive advantage is eroding? How should they restructure their organizations to concurrently disengage from the current advantage in use and mobilize resources, be they existing or newly acquired for the planned strategic move, into the next perceived advantage?

To illustrate, let us look at the case of Netflix, an American media-services provider and production company. In mid-2000s, Wilmot Reed Hastings, a cofounder, chairman and CEO of Netflix, was convinced by YouTube that streaming is going to be the preferred vehicle for users to access content, no matter what device they use, and that the DVD business will no longer be the core of Netflix's future. Following this innovative realization of the market trend, which was advanced in time among all its rivals, a spinoff, named Qwickster, was created to continue Netflix's established successful operation of DVD services with the goal of maximizing cash flow during the declining stage of its service life cycle. As Netflix leadership looked to the future, their job was to manage rapid growth and access to digital content. To avoid any potential of adverse effects between exploiting the DVD services and exploring new opportunities, the operation of Netflix was intelligently divided into two independent business branches. From the point of view of Proposition 4, it makes practical sense in terms of business operating processes. However, many customers were infuriated by the switch and by the idea that they would need to double their effort if they wanted to access movies and other content in both formats, and search for what they wanted in two different places, because choices in the DVD arena were vastly richer than those available to stream. Additionally, content providers, such as cable television and satellite dish services, 
were wary of the disruptive nature of Netflix's new move. For more details on this case, see McGrath (2013).

\section{Customer Relations and Craft of Customer Value Propositions: CASES OF ApPliCation}

All the propositions established above are derived by using the rigor of game theory and then by employing logical reasoning that is parallel to that widely used in mathematics (Kline, 1972). That is why these are generally true results unless the assumptions stated in these propositions are violated, although no hypothesis is formulated and empirically tested. As a matter of fact, hypothesis testing is simply a statistics-based approach that can be applied to uncover potential facts instead of proving any fact (Forrest et al., 2020).

As an application, this section looks at how the propositions above can be employed to establish results about the association between customer relationship management capability \& profitability, and the formulation of effective CVPs. By customer relationship management (CRM) capability, it means such a capability with that a company is able to leverage customer-level profits through:

1) Identifying the different echelons of profit potential of customers and prospects,

2) Initiating and establishing relationships with customers and prospects, and

3) Maintaining customer relations in such a way that is optimal based on the assessed profit potential of each customer echelon.

This definition of CRM capabilities embodies the recognition of the facts that beyond discrete transactions, relationships lead to profitable outcomes for companies and great satisfaction for customers (Verhoef, 2003) and that not all customers and prospects are equally attractive for a company to profitably meet their demands (Niraj et al., 2001).

Proposition 5. The more a company is capable of managing customer relationships, the more profits the company can expect to generate from both sales' revenue and margin growth.

To see why this conclusion holds true, we analyze the scenario from two angles: (1) sales revenue growth, and (2) margin growth. As for revenue growth, a company's CRM capability directs the company's attention to an understanding of how prospects and existing customers can contribute to its profitabilty differently (Reinartz et al., 2005), before any of them become a switcher (Theorem 1). So, the more a company is capable of managing customer relationships, the more adequately 
it can (a) classify prospects and existing customers into echelons of attractiveness, and (b) initiate and manage relationships with them according to their individual levels of attractiveness. In particular, at one extreme on the spectrum of attractiveness, companies can devote valuable resources on the initiation and maintenance of relationships with those high-potential prospects and existing highrevenue-producing customers. At the other extreme, without putting in any additional effort companies can simply employ pricing strategies to expand its market territory by attracting switchers that wander around the market (Theorem 1). Therefore, more CRM capable companies can expect to generate more profits or at least maintain their profitability with respect to customers of all different echelons of attractiveness. To this end, one caveat is the attempts of some companies (Ryals, 2005) that only pay attention to high-potential prospects and highly profitable customers. Such attempts generally result in fewer customers (Reinartz et al., 2005). One good case that vividly demonstrates what disasters such narrow-minded attempts might lead to is that of Pan American World Airways (Sobel, 1999), where the company focused on lucrative international air traffic without putting in any effort to develop the domestic market so that it could not stand skyrocketing energy prices and terrorist attacks. The reason behind such disastrous failures is that maintaining relationships with high profile prospects and customers of forever changing needs over a relatively long periods of time is extremely difficult, if not impossible.

As for (2) - margin growth, strong CRM capabilities help companies refine their strategies on how to deploy resources on the initiation and maintenance of relationships with prospects and existing customers respectively based on their potential and level of attractiveness. With increasing knowledge and experience on how to deal with prospects and existing customers of different attractiveness, companies are able to reduce their service costs over time (Reinartz and Kumar 2000), while increasing customer retention and more experienced users of their market offers. That helps lower companies' service costs over time (Ryals 2005). Hence, companies with strong CRM capabilities are generally able to increase their margins by continually reducing their service costs through allocating resources appropriate to the attractiveness levels of prospects and existing customer; such appropriate resource allocation in turn raises the level of satisfaction of customers in different attractiveness echelons. When appropriate relationships are maintained with those customers whose purchase decisions are not driven merely by prices, a strongly CRM-capable company will be able to realize better prices for its offers (Cao and Gruca, 2005). Therefore, Proposition 5 follows. 
This proposition is inconsistent with what is hypothesized and empirically confirmed by Morgan et al. (2009b). In particular, these scholars claim that a company's revenue growth rate is a decreasing function of CRM capability and its margin growth rate is an increasing function of CRM capability.

A concept that is closely related to that of CRM capabilities is market knowledge, which refers to knowledge about market demand regarding: (1) who customers and prospects are; (2) what their life needs and problems are; (3) who competitors are; and (4) what features their offers possess. A CVP is said to be effective to a company, if it can actually lead to additional profit for the company that is beyond the case without the CVP, after subtracting the costs for developing and implementing the CVP.

Proposition 6. Market knowledge is a market-based resource that can be employed to craft effective CVPs.

First, market knowledge is clearly a market-based resource, because it would not exist without a market. Second, let us see how effective CVPs can be formulated by using this knowledge. To do this, let us treat a focal company and its customers, both existing and potential, as input-output systems so that the company's mission represents its CVP and customers' demands as their desired inputs. Then, the communicated CVP helps associate the company's input-output flows with those of targeted customers in the market. In this systemic thinking, resource sharing is reflected in the aligned input-output flows of the company and the targeted customers. The idea of superior value is shown by the harmonious alignment of these specific input-output flows, for details, see Figure 2.

This systemic thinking indicates that for an adopted CVP to be effective, the company's input-output flows have to align with those of a sufficient number of customers. Now, the so-called market knowledge of the company can be systemically seen as the company's understanding of how the input-output flows of its rivals relate to the market and how the input-output flows of customers in the market react to the marketing activities of these companies.

Intuitively, if input-output flows $\mathrm{R}_{1}, \mathrm{R}_{2}$ and $\mathrm{R}_{3}$ in Figure 2 represent three of the rivals of the focal company, then $R_{1}$ 's territory includes $B_{1}, B_{2}$ and $B_{3}, R_{2}$ 's territory includes $C_{1}, C_{2}$ and $C_{3}$, while $R_{3}$ 'r territory includes $D_{1}, D_{2}$ and $D_{3}$. In this case, the market knowledge of the focal company will be about the associations between $\mathrm{R}_{1}$ and $\mathrm{Bs}, \mathrm{R}_{2}$ and $\mathrm{Cs}$, and $\mathrm{R}_{3}$ and Ds. Generally, when the focal company has market knowledge, it means that it knows how its rivals interact with their customers and where these interactions fall short of customer expectations. Such knowledge can help the focal company to locate its market niche(s) based on which 
customers are not adequately served by its rivals, to assess how large such consumer surplus (Theorem 1) is, and to discover what the dissatisfied customers are looking for in order to be satisfied.

These discussions above jointly explain why market knowledge is a marketbased resource the focal company can use to craft its effective $\operatorname{CVP}(\mathrm{s})$.

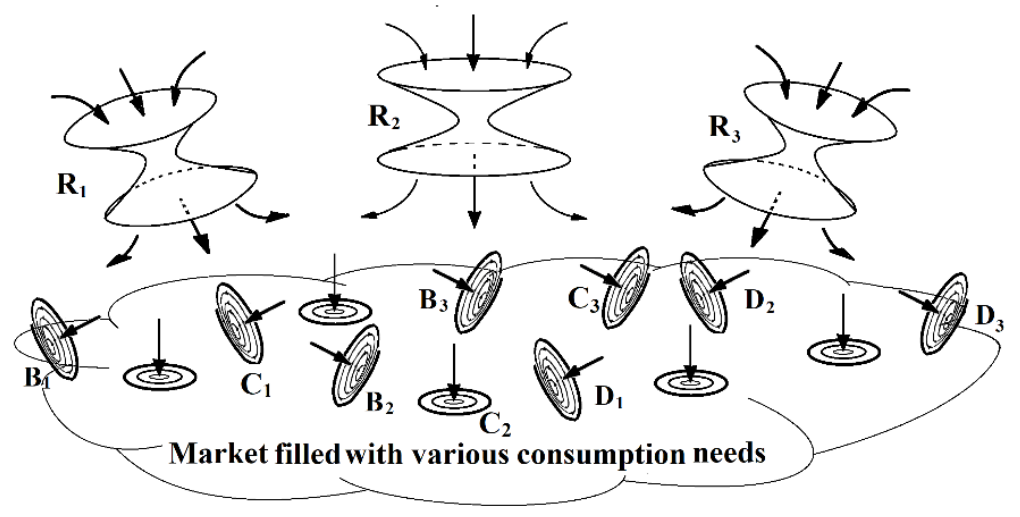

Figure 2: Rivals and their market territories

Note: Proposition 6 is different from that confirmed by Kozlenkova et al. (2014). It is also dissimilar to Payne et al. (2017), who state that market knowledge is a resource for crafting CVPs. As a matter of fact, without considering effectiveness of CVPs, one can craft a CVP without employing any market information. Even with all these key differences, we like to honor these scholars for their pioneering work related to the development of this proposition.

Proposition 7. Innovative understanding of market invitations is the key element in crafting an effective CVP.

This conclusion follows directly from Theorem 1, which implies that the market generally signals the opportunity for additional competition and innovation by showing the existence of a large consumer surplus. When the market is monopolistic, that is, in Theorem $1, n=1$, instead of switchers, the severity of customer dissatisfaction and the scale of dissatisfied customers will be used as signals of market invitation. In such a case, a surplus of producers might appear to answer the market call, depending on what a profit potential is presented, because sensing the call, entrepreneurs with different knowledge structures and background experiences will produce different versions of offers to potentially satisfy the customer demand. So, another way to sense a market invitation for innovation is the 
appearance of producer surplus. That is, an effective CVP has to be the offspring of an innovative and comprehensive understanding of market invitations.

To illustrate this proposition, let us examine a real-life example from Ye et al. (2012). Located in the northern part of the United States is a state university of over 29,000 students. Most of them are unmarried undergraduates living on tight budgets. Because of the characteristic behaviors of young and active undergraduate students, most rental properties that serve the university students do not offer easily-damaged laundry facilities. Hence, many stand-alone laundromats near the campus compete for students' business by providing self-servicing, coin-operated laundry machines. In addition, because of the long and cold winters of the region, indoor tanning is another successful business that attracts appearance-conscious college women.

Although the laundromats are different from each other in various ways, such as locations, students usually do not have particular preference of one over another, while indoor tanning salons compete for business by providing competitive prices. In other words, laundromats and indoor tanning salons respectively serve their individually different markets. In either case, customers flow from one service installment to another quite freely or depending on whose offer is more competitive.

Seeing the market invitation, as indicated by consumer surplus (Theorem 1), two entrepreneurs understood the invitation innovatively and started their independent, single-location business by jointly offering coin-operated self-service laundry facility and indoor tanning service. The innovativeness inherent to this business establishment is reflected in the following two ways: (1) it helps students save their unproductive and costly waiting time by simultaneously accomplishing two tasks - clothes washing and skin tanning, and (2) it provides male and female students with a potential opportunity to establish relationships. In particular, the greater participation of women in the tanning service, as caused by savings of time from doing two unrelated errands simultaneously, attracts to the laundry service a larger number of men who are indifferent in terms of which laundromat they go to. As a consequence of this innovative understanding of the market invitation, the combined business is able to collect higher fees from the laundry service than other standalone stores; and it sustains competitive prices for the demand of the tanning service. In particular, the demand for the tanning service is also much increased due to the heavy flow of male users of the laundromats.

\section{Conclusion}

Although the importance of market-sensing has been widely recognized in terms of improving companies' economic performance (Day, 1994; Forrest et al., 
2017; McGrath, 2013), the literature consists of inconsistent conclusions. To resolve this inconsistency, this paper goes beyond the methodology commonly used in the literature by employing game theory and the logical reasoning that is widely used in mathematics (Kline 1972). After positively achieving this said objective, this work then turns its attention to look at two closely related topics: a company's profit sources within an industry that lacks market growth, and formulation of effective CVPs. Due to the specific chosen method, established conclusions herein are free from the constraints of data and anecdotal analyses widely used in the literature. In particular, among others this work establishes the following generally-true theoretical results:

- If a company possesses a superb market-sensing capability, then it is able to create vitally important market knowledge and increase its expected profits through introducing appropriate technologies, and acquiring and deploying adequate resources (Propositions 1 and 3).

- If a company learns that its industry is lacking market growth, then its possession of a superb market-sensing capability will help grow its profit by raising margins (Proposition 3). And

- Both market knowledge, which includes market invitations, and what to make out of the knowledge are important resources a company can employ to draft an effective CVPs (Propositions 6 and 7).

Due to apparent reasons and methodological validities, implementing best practices and making statistics- or anecdote-driven decisions, as commonly employed in managerial exercises (Duan et al., 2019; McGrath, 2013), have led to widely different outcomes, some of which can be quite unexpected (Forrest et al., 2020). This fact vividly demonstrates the practical significance of this work, because our established results produce general recommendations instead of suggestions for managers and entrepreneurs. In particular, the generally-true conclusions established above lead to the following recommendations for general managerial purpose.

- To improve performance, each company needs to purposefully acquire and improve its market-sensing capability by learning which customers are underserved, why some others are dissatisfied with available market offers, and what technology can be employed to improve productivity (Propositions 1 and 2);

- When a company does not see any potential of market growth, it needs to focus on either raising the price or lowering the cost of each sold unit, or a combination of these efforts (Proposition 3), without devoting much effort on improving the sales revenue (Proposition 4);

- Any company that desires to succeed in the marketplace needs to manage its customer relationships by employing its market-sensing capability with 
resources allocated appropriately corresponding to the attractiveness levels of customers and prospects (Proposition 5); and

- Companies need to focus on formulating their CVPs by making use of their acquired market knowledge and by innovatively understanding what the knowledge implies in order to make their adopted CVPs effective (Propositions 6 and 7).

One implicit assumption behind all results established in this paper is that each company stays financially solvent through positive cash flows from the marketplace by fulfilling market demand(s) with corresponding offer(s). But in today's business landscape, this assumption is not generally true. So, for future research, one can consider developing results parallel to those developed here for companies established for other purposes, such as producing promising futures, expanding market territories, or others ( $\mathrm{Li}$ and $\mathrm{Ma}, 2015$ ). Although it is known that implementing best practices and making statistics- or anecdote-driven decisions cannot assuredly lead to desired outcomes (Lin and OuYang, 2010), an increasing number of contemporary decisions are driven by data (Duan et al., 2019; McGrath, 2013). Hence, it is very important both theoretically and practically to develop ways to demonstrate recognized best practices and statistics- or anecdote-patterns can be recommended for applications beyond the origins from which the practices and patterns are initially revealed.

\section{REFERENCES}

1. Alshanty, A.M., and O.L. Emeagwali (2019), "Market-Sensing Capability, Knowledge Creation and Innovation", Journal of Innovation \& Knowledge, Vol. 4, No. 3, pp. 171-178.

2. Ardyan, E. (2016), "Market Sensing Capability and SMES Performance", DLSU Business \& Economics Review, Vol. 25, No. 2, pp. 79-97.

3. Barney, J., and A. Arikan (2001), "The Resource-Based View: Origins and Implications", (in: M. Hitt, R. Freeman, and J. Harrison-Eds., Handbook of strategic management), Oxford, UK: Blackwell, pp. 124-185

4. Barney, J., and W. Hesterly (2012), Strategic Management and Competitive Advantage: Concepts and Cases (4th ed.), New Jersey: Pearson.

5. Bayighomog Likoum, S.W., M.D. Shamout, I. Harazneh, et al. (2018), "Market-Sensing Capability, Innovativeness, Brand Management Systems, Market Dynamism, Competitive Intensity, and Performance", Journal of the Knowledge Economy, https://doi.org/10.1007/s13132-018-0561-x

6. Bernheim, B.D., and M.D. Whinston (1990), "Multimarket Contact and Collusive Behavior", The RAND Journal of Economics, Vol. 21, No. 1, pp. 1-26. 
7. Bharadwaj, N., and Y.X. Dong (2014), "Toward Further Understanding the MarketSensing Capability-Value Creation Relationship", Journal of Product Innovation Management, Vol. 31, No. 4, pp. 799-813.

8. Cao, Y., and T.S. Gruca (2005), "Reducing Adverse Selection through Customer Relationship Management”, Journal of Marketing, Vol. 69, No. 4, pp. 219-229.

9. Clements, C., J. Alwang and R. Achdiawan (2019), "Value Chain Approaches in A Stagnant Industry: The Case of Furniture Production in Jepara, Indonesia”. Bulletin of Indonesian Economic Studies, Vol. 55, No. 3, pp. 341-365.

10. Day, G.S. (1994), “The Capabilities of Market-Driven Organizations", Journal of Marketing, Vol. 58, No. 4, pp. 37-52.

11. Dickson, P.R. (1992), "Toward a Theory of Competitive Rationality", Journal of Marketing, Vol. 56, No. 1, pp. 69-84.

12. Duan, Y.Q., J.S. Edwards and Y.K. Dwivedi (2019), “Artificial Intelligence for Decision Making in The Era of Big Data - Evolution, Challenges and Research Agenda", International Journal of Information Management, Vol. 48, No. October, pp. 63-71.

13. Dutta, S., O. Narasimhan and S. Rajiv (1999), "Success in High-Technology Markets: Is Marketing Capability Critical?” Marketing Science, Vol. 18, No. 4, pp. 547-568.

14. Einstein, A. (1997), The Collected Papers of Albert Einstein: The Berlin years (vol. 8, edited by Schulmann, R., et al.), Princeton, NJ: Princeton University Press.

15. Ferber, U., and H. Schlappa (2016), "Managing Brownfield Land in Stagnant Land Markets", (in: W.J.V. Neil and H. Schlappa-eds., Future Directions for the European Shrinking City, New York, NY: Routledge, pp. 138-154.

16. Forrest, J.Y-L. (2018), General Systems Theory: Foundation, Intuition and Applications in Business Decision Making, New York, NY: Springer.

17. Forrest, J.Y-L., J. Buttermore and T. Wajda (2017), “At Nash Equilibrium When New Market Competitions Appear?” Kybernetes: The International Journal of Cybernetics, Systems and Management Sciences, Vol. 46, No. 2, pp. 256-271.

18. Forrest, J.Y-L., J. Nicholls, K. Schimmel and S.F. Liu (2020), Managerial Decision Making: A Holistic Approach, New York, NY: Springer.

19. Forrest, J.Y-L., \& P. Tallapally (2018), "Customers are Less Patient, Sustainable Advantage Becomes Transient and the Key for Firms to Succeed in Fast Changing Markets", Journal of Business, Economics and Technology, Vol. 21, No. 1, pp. 1-14.

20. Harmancioglu, N., C. Droge and R. Calantone (2009), "Strategic Fit to Resources Versus NPD Execution Proficiencies: What are Their Roles in Determining Success?" Journal of the Academy of Marketing Science, Vol. 37, No. 3, pp. 266-282.

21. Hult, G.T. (1998), "Managing the International Strategic Sourcing Process as A MarketDriven Organizational Learning System”, Decision Sciences, Vol. 29, No. winter, pp. 193-216. 
22. Keats, B.W., and M.A. Hitt (1988), “A Causal Model of Linkages among Environmental Dimensions, Macro Organizational Characteristics, and Performance”, Academy of Management Journal, Vol. 31, No. 3, pp. 570-598.

23. Kline, M. (1972), Mathematical Thought from Ancient to Modern Times, Oxford: Oxford University Press.

24. Kowalkowski, C. (2011), "Dynamics of Value Propositions: Insights from ServiceDominant Logic", European Journal of Marketing, Vol. 45, No. 1/2, pp. 277-294.

25. Kozlenkova, I., S. Samaha and R. Palmatier (2014), "Resource-Based Theory in Marketing", Journal of the Academy of Marketing Science, Vol. 42, No. 1, pp. 1-21.

26. Le, N., H.M. Nguyen and E. Schultz (2020), "Financial Development and Productivity Growth in Stagnant Industries", SSRN: https://ssrn.com/abstract=3275778, [accessed 7.4. 2020]

27. Lecours, M. (2017), "Developing a Framework to Craft A Value Proposition", Journal of Financial Planning, Vol. 30, No. 3, pp. 23-25.

28. Li, T., and J.H. Ma (2015), "Complexity Analysis of Dual-Channel Game Model with Different Managers' Business Objectives”, Communications in Nonlinear Science and Numerical Simulation, Vol. 20, pp. 199-208.

29. Lin, Y., and S.C. OuYang (2010), Irregularities and Prediction of Major Disasters. New York: CRC Press.

30. Lindblom, A., R. Olkkonen, L. Mitronen and S. Kajalo (2008), "Market-Sensing Capability and Business Performance of Retail Entrepreneurs", Contemporary Management Research, Vol. 4, No. 3, pp. 219-236.

31. Lindstrom, M. (2005), Brand Sense: Build Powerful Brands through Touch, Taste, Smell, Sight, and Sound, Free Press, New York, NY.

32. Markman, G.D., and W.B. Gartner (2002), "Is Extraordinary Growth Profitable? A Study of Inc. 500 High-Growth Companies", Entrepreneurship: Theory and Practice, Vol. 27, No. 1, pp. 65-75.

33. McGrath, R.G. (2013), The End of Competitive Advantage: How to Keep Your Strategy Moving As Fast As Your Business, Boston: Harvard Business Review Press.

34. Morgan, N., R. Slotegraaf and D. Vorhies (2009a), "Linking Marketing Capabilities with Profit Growth", International Journal of Research in Marketing, Vol. 26, No. 4, pp. 284293.

35. Morgan, N.A., D.W. Vorhies and C. Mason (2009b), "Market Orientation, Marketing Capabilities, and Firm Performance", Strategic Management Journal, Vol. 30, No. 8, pp. 909-920.

36. Narasimhan, C. (1988), "Competitive Promotional Strategies”, Journal of Business, Vol. 61, No. 4, pp. 427-429. 
37. Niraj, R., M. Gupta and C. Narasimhan (2001), "Customer Profitability in A Supply Chain", Journal of Marketing, Vol. 65, No. 3, pp. 1-16.

38. Osterwalder, A., Y. Pigneur, G. Bernarda and A. Smith (2014), Value Proposition Design: How to Create Products and Services Customers Want, New York: Wiley.

39. Payne, A., P. Frow and A. Eggert (2017), "The Customer Value Proposition: Evolution, Development, and Application in Marketing", Journal of the Academy of Marketing Science, Vol. 45, pp. 467-489.

40. Peteraf, M., and J. Barney (2003), "Unraveling the Resource-Based Tangle", Managerial and Decision Economics, Vol. 24, No. 4, pp. 309-323.

41. Porse, H., and B. Rudolph (2017), "The Seaweed Hydrocolloid Industry: 2016 Updates, Requirements, and Outlook", Journal of Applied Phycology, Vol. 29, pp. 2187-2200.

42. Reeves, R. (1961), Reality in Advertising, Alfred A. Knopf, New York, NY.

43. Reinartz, W., and V. Kumar (2000), "The CRM Process: Its Measurement and Impact on Performance", Journal of Marketing Research, Vol. 64, No. 4, pp. 17-35.

44. Reinartz, W., J. Thomas and V. Kumar (2005), "Balancing Customer Acquisition and Retention Resources to Maximize Customer Profitability", Journal of Marketing, Vol. 69, No. 1, pp. 63-79.

45. Ryals, L. (2005), "Making Customer Relationship Management Work: The Measurement and Profitable Management of Customer Relationships", Journal of Marketing, Vol. 69, No. 4, pp. 252-261.

46. Slater, S.F., and Narver, J.C. (2000). "Intelligence Generation and Superior Customer Value”, Journal of the Academy of Marketing Science, Vol. 28, No. 1, pp. 120-127.

47. Sobel, R. (1999), When Giants Stumble: Classic Business Blunders and How to Avoid Them, Paramus, New Jersey: Prentice Hall.

48. Steffens, P., P. Davidsson and J. Fitzsimmons (2009), "Performance Configurations over Time: Implications for Growth- and Profit-Oriented Strategies", Entrepreneurship Theory and Practice, Vol. 33, No. 1, pp. 125-148.

49. Sugiyarti, G., and E. Ardyan (2017), "Market Sensing Capability and Product Innovation Advantages in Emerging Markets: The Case of Market Entry Quality and Marketing Performance of Batick Industry in Indonesia", DLSU Business \& Economics Review, Vol. 27, No. 1, pp. 175-189.

50. Tournois, L. (2016), "When Markets Stagnate: Finding New Territory through Reverse Innovation", Journal of Business Strategy, Vol. 37, No. 6, pp. 18-27.

51. Verhoef, P.C. (2003), "Understanding the Effect of Customer Relationship Management Efforts on Customer Retention and Customer Share Development", Journal of Marketing, Vol. 67, No. 4, pp. 30-45. 
52. Wouters, M., J.C. Anderson and M. Kirchberger (2018), "New Technology Startups Seeking Pilot Customers: Crafting A Pair of Value Propositions", California Management Review, Vol. 60, No. 4, pp. 101-124.

53. Ye, G.L., R.L. Priem and A.A. Alshwer (2012), “Achieving Demand-Side Synergy from Strategic Diversification: How Combining Mundane Assets Can Leverage Consumer Utilities”, Organization Science, Vol. 23, No. 1, pp. 207-224. 